\title{
Factors influencing visual outcome in anisometropic amblyopes
}

\author{
C J Cobb, K Russell, A Cox, C J MacEwen
}

Br J Ophthalmol 2002;86:1278-1281

See end of article for authors' affiliations

.....................

Correspondence to: Dr Caroline Cobb,

Department of

Ophthalmology, Ninewells

Hospital and Medical

School, Dundee DDI 9SY;

alan.cox@tuht.scot.nhs.uk

Accepted for publication 17 April 2002

\begin{abstract}
Aim: To identify which factors influence the final visual acuity in children with anisometropic amblyopia.

Methods: A retrospective analysis of 112 children with anisometropic amblyopia, identified from examining all case notes of children who had failed preschool or school screening.

Results: The age at presentation had no effect on the final visual outcome $(p=0.804)$. Both the degree of refractive error and the degree of anisometropia at presentation correlated with final visual acuity $(p<0.001$ and $p=0.001)$. Those with strabismus had a poorer final outcome.

Conclusions: The age at presentation of a child with anisometropic amblyopia appears to have no significant effect on the final visual acuity. The amount of refractive error and degree of anisometropia at presentation do correlate strongly with final visual acuity. This would suggest, firstly, that children with poorer visual acuity at presentation and higher degrees of anisometropia should be treated more aggressively and that, secondly, children with anisometropic amblyopia should be treated regardless of age.
\end{abstract}

t $\mathrm{t}$ is well recognised that anisometropia can lead to amblyopia. The exact mechanism is unclear, although von Noorden suggested that there may be active inhibition of the fovea to overcome the interference caused by attempting to superimpose a focused image in one eye and a defocused image in the other. ${ }^{1}$ There is now evidence that factors causing amblyopia may in themselves also cause anisometropia. ${ }^{2}$

The natural history of anisometropia is poorly documented. Clinical evidence demonstrates that adults with anisometropia, uncorrected until after the age of visual maturation, demonstrate some degree of amblyopia. ${ }^{3}$ Anisometropia was found to be responsible for $50 \%$ of amblyopia in one study looking at the prevalence and causes of amblyopia in an adult population. ${ }^{4}$ Examination of the natural history of anisometropia in children non-compliant with treatment showed that after a year of follow up the vision in the amblyopic eye remained unchanged or had worsened. ${ }^{5}$

Children with anisometropia, but no squint, have no external signs which would indicate the potential to develop amblyopia. Therefore, such children are not usually identified at an early age without some form of visual screening.

This study therefore set out to identify whether the age of detection of anisometropic amblyopia has any effect on the final visual outcome. In addition, the degree of anisometropia, level of refractive error, presence or absence of squint, and initial visual acuity were analysed to establish if they had any influence on the final visual outcome in children with anisometropic amblyopia.

\section{METHODS}

The case notes of children referred to the eye clinic from the Tayside preschool and school screening service between 1972-95 were reviewed retrospectively to identify those presenting with anisometropia and amblyopia. Until 1979 preschool and school screening was carried out by the school nurse. From 1979 onwards this screening was carried out by orthoptists. Children were referred to this clinic if the vision at screening, in one or both eyes, was found to be less than 6/9.

Anisometropia was defined as the difference in the refractive error between the eyes of 2.0 dioptres or greater of sphere or cylinder. Amblyopia was defined as a difference in initial corrected visual acuity of two lines or greater when measured using a Snellen chart in the majority of cases, and, in the younger children, the Sheridan-Gardiner test. All children underwent an orthoptic examination before cycloplegic refraction. The refraction was carried out by one of three doctors. Treatment consisted of a full spectacle correction followed by, if necessary, occlusion with patching. Occlusion was for a limited part of waking hours, the duration determined by the degree of amblyopia and response to treatment.

Children were excluded if they had any other ocular pathology, previous ocular surgery, previous ocular trauma, or incomplete documentation in their case notes. All children whose visual acuity improved with glasses immediately were also excluded as it was assumed that the reduction in vision in these cases was due to the refractive error and not amblyopia.

The following information was recorded from the notes:

(1) age at presentation

(2) initial visual acuity and first corrected visual acuity

(3) type and degree of anisometropia

(4) the refractive error in each eye at presentation and discharge

(5) treatment modality (glasses and/or occlusion)

(6) the presence and type of squint.

The difference in visual acuity at presentation and discharge was calculated by converting the visual acuity to logMAR (the logarithm of the Snellen reciprocal $)^{6}$ before calculating the difference.

\section{Statistical methods}

Statistical analysis was carried out using an sPss data spread sheet. Multiple regression analysis was performed utilising hierarchical stepwise forced entry to determine the influence of each factor on final visual acuity. However, significant multicollinearity was encountered between the degree of anisometropia and the spherical equivalent (Pearson's correlation coefficient $0.744, \mathrm{df}=112, \mathrm{p}<0.001$ ). In this situation it is impossible to accurately interpret the model without excluding one of the factors and so simple regression was used 


\begin{tabular}{|lc|}
\hline Table 1 & Demographics of group \\
\hline Total & $\mathrm{n}=112$ \\
\hline Strabismus & 53 \\
$\quad$ Esotropia & 13 \\
Exotropia & 3 \\
$\quad$ Micro-esotropia & 34 \\
$\quad$ Micro-exotropia & 3 \\
Refraction & \\
$\quad$ Hypermetropes & 97 \\
Myopes & 14 \\
Mixed astigmatism & 1 \\
Age (years) & $3-12$ \\
$\quad$ Range & 5.33 \\
Mean & \\
Ambylopic eye & $39(35 \%)$ \\
Right & $73(65 \%)$ \\
Left & \\
\hline & \\
\hline
\end{tabular}

instead. This may overestimate the contribution of both of these factors; however, this error will not influence the contribution of other factors.

Standardised residuals (difference between the value predicted by the model and the observed value for that case) with a magnitude greater than 2 SD were inspected. Cook's and Mahalanobi's distances and the centred leverage values for these cases were determined to decide whether or not the case should be excluded. It was not felt that any case exerted an undue influence on the model and so no cases were removed.

Analysis was also performed on the group consisting of non-strabismic anisometropes and anisometropes with a microdeviation as this is the group that would only be identified by screening.

When interpreting the results it should be remembered that a Snellen acuity of 6/6 has a $\log$ MAR value of 0 and a Snellen acuity of 6/60 has a logMAR value of 1.0. Therefore, when interpreting the value for $\beta$ (the gradient of the slope in the regression solution) a positive value indicates that an increase in the variable in question predicts a poorer final visual acuity. Absolute values of $\beta$ are dependent on the units of the measurement and so standardised $\beta$ is quoted to allow direct comparison between variables.

\section{RESULTS}

The notes of Tayside children referred from preschool and school screening with reduced vision in one or both eyes were examined and from these 112 children were identified as having anisometropic amblyopia (Table 1 ).

The influence of factors on the final visual acuity are summarised in Table 2. There was no correlation between age of presentation and final visual acuity in the amblyopic eye, (standardised $\beta-0.024, \mathrm{p}=0.804$ ) (Fig 1). However, there was found to be a strong inverse linear trend correlating refractive error (spherical equivalent) and degree of anisometropia with the final visual acuity (standardised $\beta 0.492, \mathrm{p}>0.001$ and standardised $\beta 0.315 \mathrm{p}=0.001$ respectively) (Figs 2 and 3).

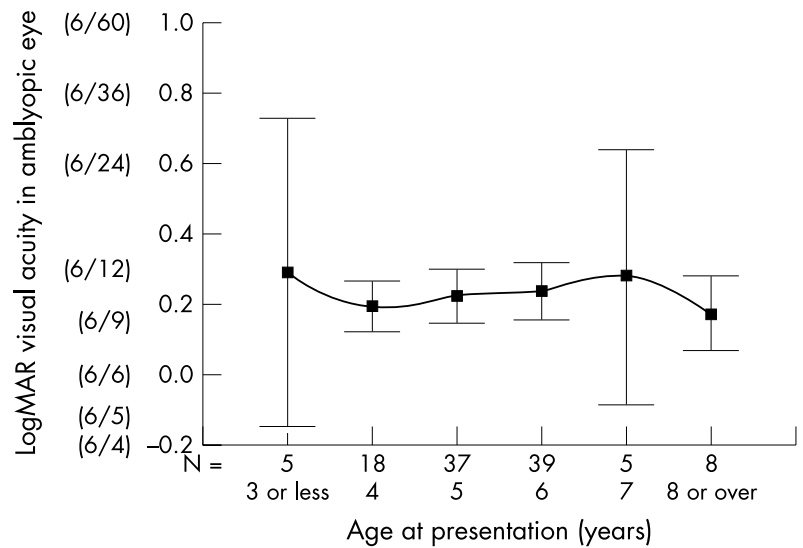

Figure 1 Correlation between the age at presentation and visual acuity in amblyopic eye at time of discharge (mean and 95\% Cl) for patients with anisometropic amblyopia. Scale is in logMAR units and Snellen equivalent is included for reference. $\mathrm{N}$ is the number of cases presenting at that age.

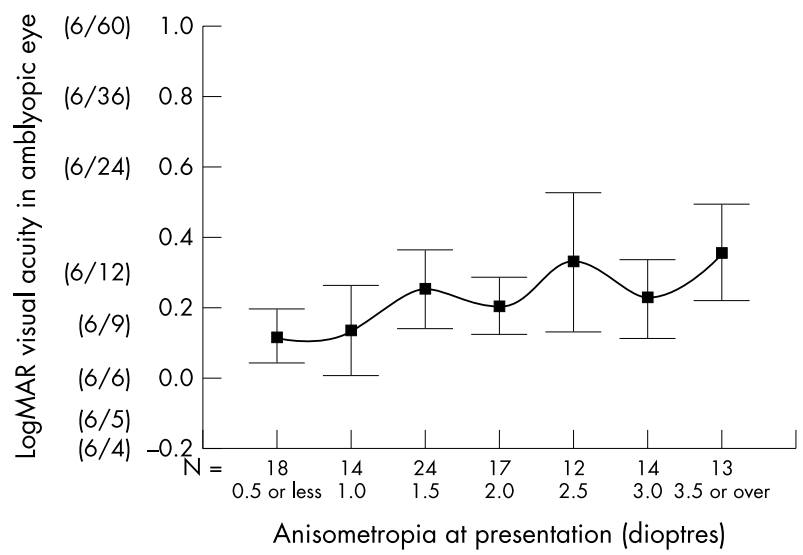

Figure 2 Correlation between the degree of anisometropia at presentation and the final visual acuity (mean and 95\% Cl) in the amblyopic eye. Scale is in logMAR units and Snellen equivalent is included for reference. $\mathrm{N}$ is the number of cases presenting with that degree of anisometropia.

Subgroup analysis was also performed dividing the group into strabismic hypermetropes (including those with a microtropia), non-strabismic hypermetropes, and non-strabismic myopes. There were only four patients with nonhypermetropic strabismus and so it was felt that no useful conclusions could be drawn from this subgroup. These trends are reported in Table 3. Of note is the lesser contribution of anisometropia to amblyopia in strabismic hypermetropes (standardised $\beta$ 0.160, $\mathrm{p}=0.268$ ). The high $\mathrm{R}^{2}$ values for spherical equivalent and anisometropia in the anisometropic myopes illustrate the problem of multicollinearity-that is, patients with a large spherical equivalent also have a high degree of anisometropia.

Table 2 Influence of factors in explaining final visual acuity (logMAR) in anisometropic amblyopia $(n=112)$

\begin{tabular}{|c|c|c|c|c|c|c|}
\hline & $\mathrm{R}^{2}(\%)$ & $\beta$ & $95 \% \mathrm{Cl}$ for $\beta$ & Standardised $\beta$ & t statistic & Significance \\
\hline Presence of squint & $0.178(18 \%)$ & 0.193 & 0.12 to 0.27 & 0.422 & 4.88 & $p<0.001$ \\
\hline Spherical equivalent & $0.242(24 \%)$ & 0.063 & 0.04 to 0.08 & 0.492 & 5.93 & $p<0.001$ \\
\hline Anisometropia & $0.099(10 \%)$ & 0.050 & 0.02 to 0.08 & 0.315 & 3.48 & $\mathrm{p}=0.001$ \\
\hline Age at presentation & 0.001 (>1\%) & -0.004 & -0.03 to 0.03 & -0.024 & -0.25 & $p=0.804$ \\
\hline
\end{tabular}

$\mathrm{R}^{2}$ statistic expressed as a percentage denotes the amount of variability in the final vision that this particular factor accounts for. Correlation coefficient $\beta$ is expressed in standard deviations to allow direct comparison of the gradients of the relative slopes. 


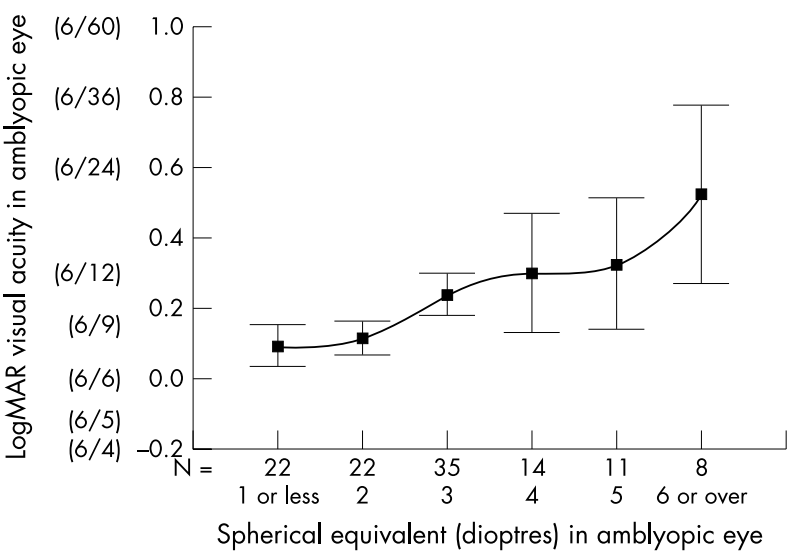

Figure 3 Correlation between the spherical equivalent at presentation in the amblyopic eye and the final visual acuity (mean and $95 \% \mathrm{Cl}$. Scale is in logMAR units and Snellen equivalent is included for reference. $\mathrm{N}$ is the number of cases presenting with that spherical equivalent in the amblyopic eye

Regression analysis was carried out to examine whether the degree of anisometropia, spherical equivalent, presence of strabismus, or initial visual acuity varied significantly with age at presentation. Anisometropia, spherical equivalent, and presence of a squint did not vary with age of presentation (standardised $\beta$ 0.092, $\mathrm{p}=0.319$, standardised $\beta-0.047$, $\mathrm{p}=0624$ and standardised $\beta-0.024, \mathrm{p}=0.802$ respectively). The same was true for the initial visual acuity both at the first visit and at the first visit after starting spectacle correction (standardised $\beta-0.140, p=0.140$ and standardised $\beta-0.069$, $\mathrm{p}=0.469$ respectively).

Mean final visual acuity was significantly worse in strabismic versus non-strabismic children. The mean final visual acuity in those with strabismus was $\log$ MAR 0.33 (Snellen equivalent 6/12) and the mean final visual acuity in those without was logMAR 0.14 (6/9-6/7.5), this difference was significant, $(\mathrm{p}<0.001)$ using the independent sample $t$ test. In the non-strabismic group both hypermetropes and myopes attained a good final acuity $0.14(6 / 9-6 / 7.5)$ and 0.14 $(6 / 9-6 / 7.5)$, respectively $(p=0.91)$

The mean improvement in visual acuity was $\log$ MAR -0.47 in strabismic and $\log M A R-0.45$ in non-strabismic patients $(p$ $=0.55)$. This is equivalent to an average improvement of about four lines in Snellen acuity.

Two thirds of the strabismic patients had microdeviations which, like those with pure anisometropia and no strabismus, are only likely to be identified with a screening programme. For this reason analysis of purely anisometropic amblyopes and anisometropes with a microdeviation were compared and revealed similar trends with no association between age at presentation and final acuity in the amblyopic eye (standardised $\beta-0.033, p=0.752$ ). This group is summarised in Table 4 .

\section{DISCUSSION}

There is little doubt that anisometropia is a cause of amblyopia, and that vision in an amblyopic eye will remain poor without treatment. ${ }^{5}$ Significant anisometropia present from an early age is likely to persist ${ }^{3}$ and, as a significant proportion of children with anisometropia have no squint, they would therefore remain unnoticed in the absence of a screening programme. Treatment of amblyopia is ineffective in adult life but effective in childhood. ${ }^{78}$ The prevalence and depth of amblyopia have been shown to be markedly reduced by screening 4-5 year olds in a cohort of 3126 Swedish children. ${ }^{9}$ For these reasons a screening programme to detect anisometropic amblyopia in childhood is justified and logic would dictate that earlier treatment of amblyopia would result in a better final visual acuity.

The systematic review by Snowdon and Stewart-Brown ${ }^{10}$ evaluated 58 papers on childhood screening. It concluded that there is insufficient evidence to support a preschool vision screening programme and that every effort should be made to rectify this. It further recommends that "purchasers and providers should be appraised of the result of this review and

Table 3 Subgroup analysis of factors influencing the final visual acuity in the amblyopic eye

\begin{tabular}{|c|c|c|c|c|c|c|c|}
\hline Subgroup & Factor & $\mathrm{R}^{2}(\%)$ & $\beta$ & $95 \% \mathrm{Cl}$ for $\beta$ & Standardised $\beta$ & t statistic & Significance \\
\hline \multirow[t]{2}{*}{$\begin{array}{l}\text { Strabismic } \\
\text { hypermetropes }(n=49)\end{array}$} & $\begin{array}{l}\text { Spherical equivalent in } \\
\text { amblyopic eye }\end{array}$ & $0.164(16 \%)$ & 0.065 & 0.02 to 0.11 & 0.405 & 3.07 & $p<0.01$ \\
\hline & $\begin{array}{l}\text { Anisometropia } \\
\text { Age at presentation }\end{array}$ & $\begin{array}{l}0.025(3 \%) \\
0.000(<1 \%)\end{array}$ & $\begin{array}{r}0.032 \\
-0.002\end{array}$ & $\begin{array}{l}-0.02 \text { to } 0.09 \\
-0.48 \text { to } 0.43\end{array}$ & $\begin{array}{r}0.160 \\
-0.016\end{array}$ & $\begin{array}{r}1.12 \\
-0.11\end{array}$ & $\begin{array}{l}p=0.27 \\
p=0.91\end{array}$ \\
\hline \multirow[t]{2}{*}{$\begin{array}{l}\text { Non-strabismic } \\
\text { hypermetropes }(n=48)\end{array}$} & $\begin{array}{l}\text { Spherical equivalent in } \\
\text { amblyopic eye }\end{array}$ & $0.156(16 \%)$ & 0.048 & 0.02 to 0.08 & 0.395 & 2.92 & $p<0.01$ \\
\hline & $\begin{array}{l}\text { Anisometropia } \\
\text { Age at presentation }\end{array}$ & $\begin{array}{l}0.174(17 \%) \\
0.000(<1 \%)\end{array}$ & $\begin{array}{r}0.055 \\
-0.001\end{array}$ & $\begin{array}{r}0.02 \text { to } 0.09 \\
-0.03 \text { to } 0.03\end{array}$ & $\begin{array}{r}0.417 \\
-0.006\end{array}$ & $\begin{array}{r}3.11 \\
-0.04\end{array}$ & $\begin{array}{l}p<0.01 \\
p=0.97\end{array}$ \\
\hline \multirow[t]{2}{*}{$\begin{array}{l}\text { Non-strabismic } \\
\text { myopes }(n=11)\end{array}$} & $\begin{array}{l}\text { Spherical equivalent in } \\
\text { amblyopic eye }\end{array}$ & 0.714 (71\%) & 0.055 & 0.03 to 0.08 & 0.845 & 4.74 & $p=0.001$ \\
\hline & $\begin{array}{l}\text { Anisometropia } \\
\text { Age at presentation }\end{array}$ & $\begin{array}{l}0.774(77 \%) \\
0.001(<1 \%)\end{array}$ & $\begin{array}{r}0.084 \\
-0.006\end{array}$ & $\begin{array}{r}0.05 \text { to } 0.12 \\
-0.13 \text { to } 0.12\end{array}$ & $\begin{array}{r}0.880 \\
-0.036\end{array}$ & $\begin{array}{r}5.55 \\
-0.11\end{array}$ & $\begin{array}{l}p<0.001 \\
p=0.92\end{array}$ \\
\hline
\end{tabular}

$R^{2}$ statistic expressed as a percentage denotes the amount of variability in the final vision that this particular factor accounts for Correlation coefficient $\beta$ is expressed in standard deviations to allow direct comparison of the gradients of the relative slopes.

Table 4 Influence of factors in explaining final visual acuity (logMAR) in patients with non-strabismic anisometropic amblyopia or with a microtopia $(n=95)$

\begin{tabular}{|c|c|c|c|c|c|c|}
\hline & $\mathrm{R}^{2}(\%)$ & $\beta$ & $95 \% \mathrm{Cl}$ for $\beta$ & Standardised $\beta$ & t statistic & Significance \\
\hline Spherical equivalent & $0.259(26 \%)$ & 0.062 & 0.04 to 0.08 & 0.492 & 5.74 & $p<0.001$ \\
\hline Anisometropia & $0.146(15 \%)$ & 0.055 & 0.03 to 0.08 & 0.382 & 4.01 & $p<0.001$ \\
\hline Age at presentation & 0.001 (<1\%) & -0.005 & -0.03 to 0.02 & -0.033 & -0.32 & $p=0.752$ \\
\hline
\end{tabular}

$R^{2}$ statistic expressed as a percentage denotes the amount of variability in the final vision that this particular factor accounts for. Correlation coefficient $\beta$ is expressed in standard deviations to allow direct comparison of the gradients of the relative slopes. 
advised not to implement new pre-school screening programme. Providers currently offering screening programmes should consider discontinuing them."

This systematic review has stimulated further research into the optimum time to screen children for visual defects. In our study, age at presentation (range 3-12 years) was not found to be a significant factor in predicting final visual outcome in children with anisometropic amblyopia. Other studies have identified similar results ${ }^{11-13}$ but Sen $e t$ al ${ }^{14}$ reported that the older the patient at presentation the greater the degree of amblyopia. However, over $65 \%$ of his group were teenagers and only $4 \%$ were under the age of 6 at the time of diagnosis.

In our study, it could be postulated that children with higher degrees of anisometropia had been detected at an earlier age. This would leave only mild anisometropia in older children, who have a good prognosis and thus explain why age of presentation is not predictive of final visual acuity. However, the results indicate that the degree of anisometropia did not vary significantly with age at presentation.

Another explanation for the lack of correlation between the age at presentation and the final visual acuity could be that strabismus, which has a poorer visual prognosis, ${ }^{7}$ would be detected earlier and so skew the figures. Certainly those with any form of strabismus did have a significantly poorer final visual acuity in the amblyopic eye than those without strabismus. However, there was no significant difference in the age of presentation of those with strabismus and those without. In addition, analysing both strabismic and non-strabismic amblyopia separately did not alter the results.

A further argument is that the method of testing visual acuity would penalise those who presented early. However, regression analysis failed to demonstrate better visual acuity at presentation with increasing age at either the first visit or the first visit after spectacle correction and so patients presenting early were not artificially penalised by the method of testing.

The degree of anisometropia was highly significant in predicting final visual outcome for both hypermetropes and myopes in this study. A study by Townsend et al, ${ }^{15}$ examining 35 untreated pure anisometropic amblyopic patients aged between 7 and 70, also found that depth of amblyopia strongly correlated with the amount of anisometropia, and other studies support this finding. ${ }^{14}{ }^{16}$ In contrast, Malik et a ${ }^{17}$ examined 212 patients with anisometropia and found that there was no correlation between degree of anisometropia and depth of amblyopia in those with central fixation. In this study, however, the myopes and hypermetropes were not examined independently.

Overall, only $22 / 112$ (19\%) of our patients failed to achieve a final visual acuity equivalent to $6 / 12$ or better in the amblyopic eye independent of the age of presentation, indicating that active treatment is highly successful. For the entire group the average improvement in acuity was about four lines of Snellen acuity.

These results add to the previous literature by indicating that spectacle correction should be given for reduced vision in all children with anisometropia independent of age at presentation. Poorer visual acuity at diagnosis, higher refractive error and a degree of anisometropia are all associated with a poorer prognosis and these children should be closely monitored and given more aggressive occlusion therapy at an early stage if unresponsive to standard treatment. The age at presentation did not have a significant effect on the final visual outcome, which suggests that the time at which screening is carried out may not be as critical for this group.

Therefore, screening for this common condition should ideally be carried out on one occasion, when the likelihood of the child attending is high, at an age when they can give reliable responses and, should occlusion be necessary, this will not interfere with schooling. This is consistent with the recommendations issued by the children's subgroup of the National Screening Committee of the United Kingdom. ${ }^{18}$

\section{ACKNOWLEDGEMENTS}

The authors would like to thank Dr Ron Brown of Dundee University, and Dr Chen at Ninewells Hospital for all their help and advice regarding the statistics.

\section{Authors' affiliations}

C J Cobb, K Russell, A Cox, C J MacEwen, Department of Ophthalmology, Ninewells Hospital and Medical School, Dundee DDI 9SY, UK

\section{REFERENCES}

1 Von Noorden. Binocular vision and ocular motility. 4th ed. St Louis: CV Mosby, 1990:208-13.

2 Fielder AR, Moseley M. Anisometropia and amblyopia-chicken or egg? Br J Ophthalmol 1996;80:857-8.

3 Abrahamsson $\mathbf{M}$, Siostrand J. Natural history of infantile anismetropia. Br J Ophthalmol 1996;80:860-3

4 Attebo K, Mitchell P, Cumming R, et al. Prevalence and causes of amblyopia in an adult population. Ophthalmology 1998;105:154-9.

5 Simons K, Preslan M. Natural history of amblyopia untreated owing to lack of compliance. Br J Ophthalmol 1999:83:582-7.

6 Ferris FL, Kassof A, Bailey I. New visual acuity charts for clinical research. Am. J. Ophthalmol 1982;94:91-6.

7 Woodruff G, Hiscox F, Thompson JR, et al. Factors affecting the outcome of children treated for amblyopia. Eye 1994;8(pt 6):627-31.

8 Lithander J, Siöstrand J. Anisometropic and strabismic ambylopia in the age group 2 years and above: a prospective study of the results of treatment. Br J Ophthalmol 1991;75:111-16.

9 Gottlob I. The detection, prevention, and rehabilitation of amblyopia. Curr Opin Ophthalmol 1999;10:300-4.

10 Snowdon SK, Stewart-Brown SL, Preschool vision screening: results of a systematic review. York: NHS Centre for Reviews, 1997 (CRD Report 9)

11 Kutschke PJ, Scott WE, Keech RV. Anisometropic amblyopia. Ophthalmology 1991;98:258-63.

12 Hardman Lea SJ, Rubinstein JLMP. The sensitive period for anisometropic amblyopia. Am J Ophthalmol 1966;62:575-9

13 Pollard ZF, Manley D. Long term results in the treatment of unilateral high myopia with amblyopia. Am J Ophthalmol 1974;78:397-9.

14 Sen DK, Anisometropic amblyopia. J Pediatr Ophthalmol Strabismus 1980;17:180-4.

15 Townshend AM, Holmes JM, Evans LS. Depth of anisometropic amblyopia and difference in refraction. Am J Ophthalmol 1993; 11 16:431-6

16 Jampolsky A, Flom BC, Weymouth FW, Moses LE. Unequal corrected visual acuity as related to anisometropia. Arch Ophthalmol 1955;54:893.

17 Malik SRK, Gupta AK, Choudhry S. Anisometropia. Its relation to amblyopia and eccentric fixation. Br J Ophthalmol 1968;52:773.

18 Rahi JS, Williams $\mathrm{C}$, Bedford $\mathrm{H}$, et al. Screening and surveillance for ophthalmic disorders and visual deficits in children in the UK. Br J Ophthalmol 2001;85:257-9. 